\title{
ELECTROMYOGRAPHIC STUDIES OF EMOTIONAL STATES IN NORMAL SUBJECTS
}

\author{
BY \\ P. P. NEWMAN
}

From the Department of Physiology, School of Medicine, Leeds, 2

Many methods have been described for assessing personality in both normal and abnormal populations. Among these, the word-association test is a simple procedure, but of limited value in clinical diagnosis. In most individuals the emotional reaction to stimulus words may be successfully controlled, so that no visible reaction can be observed or accurately measured. Several modifications have been proposed with a view to establishing the validity and usefulness of the test. Peterson and Jung (1907) correlated the reaction times of stimulus words with a pneumograph and the skin galvanometer. Luria (1932) measured the response to emotional situations by observing muscular activity recorded through a sensitive tambour; the technique showed that muscular tension was directly related to subjective feeling. This principle was applied to the study of handwriting by Ruesch and Finesinger (1943), but later improvements in methods of investigation allowed more accurate measurements to be made than was possible by the study of pressure points in handwriting. Thus Lundervold (1952) did an electromyographic investigation of limb and trunk muscles to determine whether muscular activity was related to emotional excitement. His subjects were sitting down and using a typewriter. During periods of emotional tension action potentials were recorded continuously, but in relaxed subjects there was complete electrical inactivity, except when the keys of the typewriter were being struck. This is in accordance with the findings of Weddell, Feinstein, and Pattle (1944) who stated that no electrical activity could be recorded from a voluntary muscle which was completely relaxed. Liberson (1945) combined the wordassociation test with electroencephalography, and found that stimulating words were followed by a depression of alpha rhythm. The emotional value of different words could be measured against the persistence of this depression, and its duration corresponded to the reaction time of the subject.
The correlation between emotional reactions and muscle tension was demonstrated by Davis and Malmo (1951), who recorded electromyographic changes during the interview of two patients with anxiety states. Leads were taken from forehead, neck, and arm muscles. In these subjects, headache was a predominant symptom, and they found a considerable rise of tension in the forehead muscles. The response to treatment was characterized by a general reduction of muscle activity recorded at later interviews.

The present work was a development in techniqued in which surface electrodes were applied to the scalp as in electroencephalography. The electrodes were placed over the temporal muscle, as this was found to give better results than other areas of the scalp In a relaxed subject only E.E.G. recordings were obtained, but in response to a stimulus word action potentials from the temporal muscle were recorded in addition, and the emotional value of different words could then be measured in terms of the electromyogram. One value of this method was that the assessment of different subjects could be standardized according to the amplitude, frequency, and duration of the muscle action potentials.

\section{Methods}

The subject was made comfortable in an easychair with arm rests. A warm temperature was maintained, and noise was eliminated as much as possible. Continuous records were taken on an inkrecording unit coupled with a cathode-ray oscilloscope. The stimulating words were prepared from a modified Jung list, containing "emotional" and " neutral" words in random order. Each word was repeated once and the subject was asked to concentrate on its meaning. There was an interval of 15 seconds between each word. The subject remained silent, and the association method was not used. In some experiments, instead of using stimulus words, past emotional experiences of the 
subject were reproduced by suggestion and an attempt was made to correlate the electromyographic responses with possible changes in $\mathrm{CO}_{2}$ alveolar tension. Alveolar air was collected in sampling tubes, and the concentration of $\mathrm{CO}_{\varepsilon}$ was determined by the Haldane gas analysis apparatus.

\section{Results}

An unselected group of volunteers was examined by this method. Although many words were often followed by a depression of alpha activity, action potentials, recorded as muscle spikes, were the changes studied in the electroencephalogram. No muscle spikes were seen in the relaxed subject, but increased tension, resulting from a stimulus word, produced rapid oscillations in the tracing, due to a succession of action currents in the scalp muscles. The subject was unaware of this effect and showed no outward sign of emotion.

\section{Case Records}

Series A.- In this series a list of 100 words was read to each subject, and any action potentials recorded were correlated with the emotional value of the word.

Case P. C.-This was an educated man, age 29 , single. The electroencephalogram was normal, and no muscle potentials could be found in the record. There was, however, a depression of alpha rhythm lasting five to 15 seconds following the stimulus words " angry", " excited ", and "quarrel " (Fig. 1). The eyes remained closed throughout the experiment.

Although the words "excited", " anger", and "quarrel" were the only stimulus words giving a positive reaction, the subject could not recall any incident which might have thrown light on a past situation, or have given some insight into his personality; this was not further investigated.

Case I. G.-This subject was a technician, of average intelligence, age 19, and single. The subject reacted to the word "speech" showing a number of muscle spikes in the electroencephalogram (Fig. 2). The spikes persisted for 15 seconds until the next word of the test was given. Afterwards he volunteered the information that he disliked the idea of giving a speech.

Case S. R.-This was a plumber, age 41 , who was married. Reaction was obtained to the stimulus word "family" (Fig. 3). It persisted for seven seconds. On repeating the word "family" a similar action was recorded. None of the other stimulus words used produced muscle potentials. The subject was not further investigated.

Case -. T.-This man was a schoolmaster, age 33, and married. Marked reactions were obtained with the words " hospital", " blood", and "operation" (Fig. 4). Between each word several neutral words gave no response. This subject stated afterwards that he had been involved in a motor cycle accident, in which a child had been seriously injured.

Case $J$. O'B.-This subject was a typist, age 22, and single. Positive reactions were obtained for the stimulus words "skin" and "rash" (Fig. 5). The subject afterwards stated that she had suffered for many years from an allergic condition on her face.

Case M. W.-In this subject, a housewife, age 25, reactions followed the stimulus words "dance-hall", " husband", and " fight " (Fig. 6). The subject was able to recall an unpleasant incident that occurred three years previously when she was engaged to be married.

The records taken in Series A showed that a stimulating word was followed after a short latent period of less than one second by a succession of muscle action potentials, which were superimposed on the electroencephalogram. A non-stimulating word had no such effect. The personal history of the subjects was not taken, but in a number of cases they were able to recall some incident which correlated closely with the myographic responses.

Series B.-In this series, a continuous record was taken while the subject concentrated on a specific emotional experience. The following technique was adopted. The subjects were asked to name any object or situation that was particularly distasteful to them or one that aroused a feeling of passion, revulsion, or horror. These incidents were then described by the operator with the intention of reenacting the scene or building up a vivid emotional picture.

Case W. H.-A commercial secretary, age 26, married, had a particular dislike for spiders. The electroencephalogram was normal and no responses were obtained to a word-list test. It was suggested that she saw a spider on a wall, that it suddenly jumped onto her leg, crawled onto her arm and neck, that it was a big, hairy spider, she was unable to brush it off, and finally that it was dead and out of sight. Fig. 7 shows the electromyographic response. The subject showed no visible signs of emotion. The pulse and respiratory rates remained constant throughout the experiment.

Case G. S.-A medical student, age 22 , was a highly strung individual, tense and emotional, especially before sitting for an examination. A record was taken during successive periods of suggested excitement and calm. Fig. 8 shows how the electromyographic responses can be repeated at will.

Case L. H.-A housewife, age 36 , had recently been discharged from the skin department of a hospital, where she had been treated for angioneurotic oedema. She had been free from symptoms for the past six months. A recurrence of the skin condition was suggested, and samples of alveolar air were taken during the course of the 
(a)

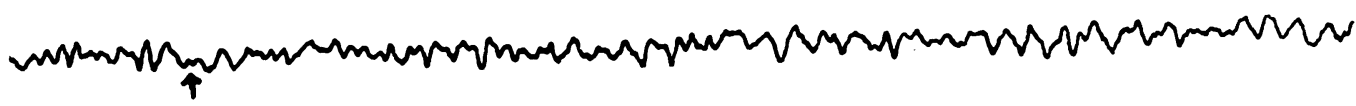

(b)

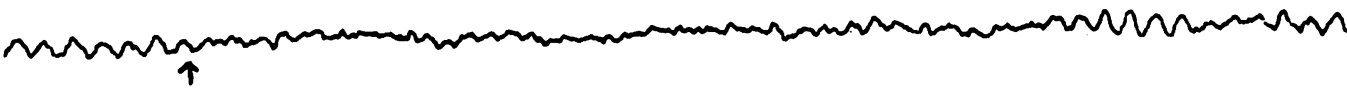

(c)

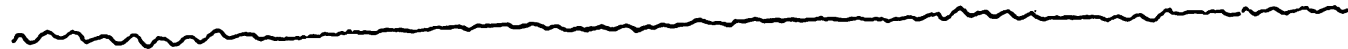

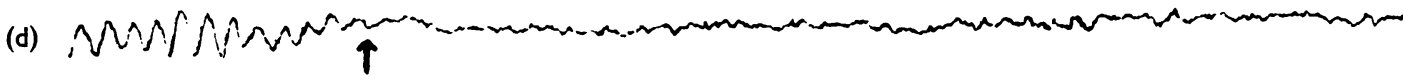

(e)

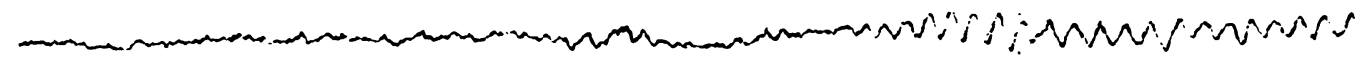

\section{$\int 50$ uv. \\ I SEC.}

FIG. 1.-E.E.G. showing depression of alpha rhythm following a stimulus word marked by the arrow.

(a) "Flower"-no depression; (b) "excited"- -depression lasting 3 sec.; (c) " anger"--depression lasting 5 sec.; (d) and (e) continuous record. Stimulus word " quarrel". Depression, 8 sec.

(a)

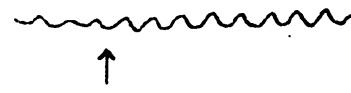

(b)
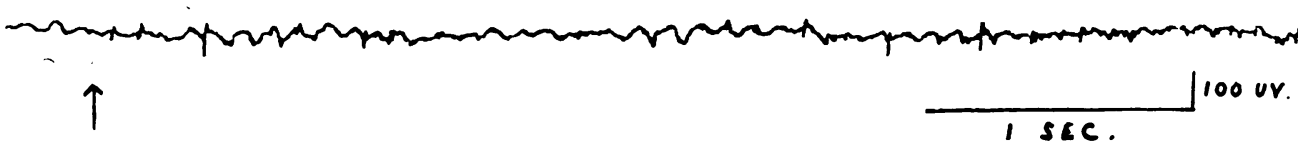

FIG. 2.-E.E.G. showing muscle action potentials.

(a) Stimulus word "girl-friend"-no reaction; (b) stimulus word "speech"-random spikes of low voltage.

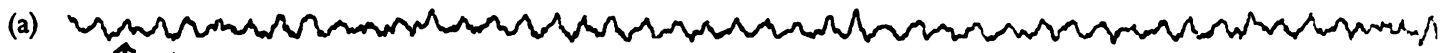
$\uparrow$

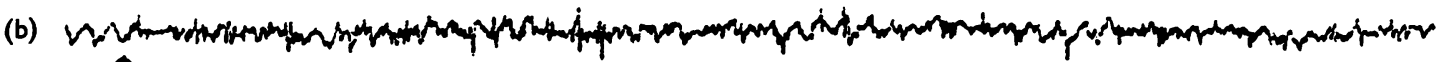
$\uparrow$

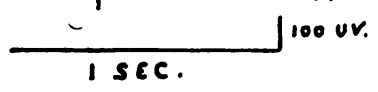

Fig. 3.-Electromyogram from Case S.R. Right temporo-parietal lead.

(a) Some neutral word giving no response ; (b) response following stimulus word "family". 


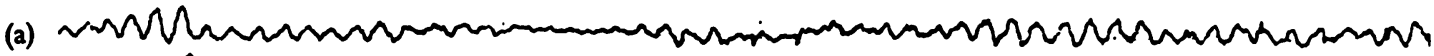
$\uparrow$

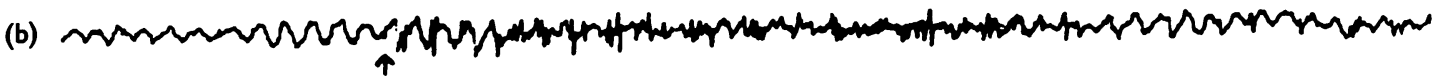

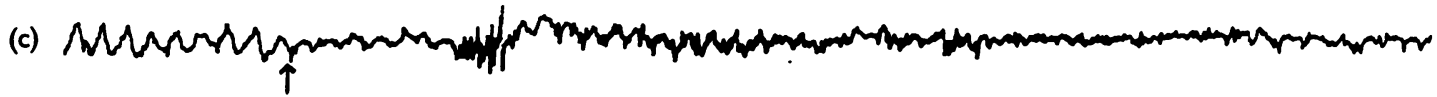

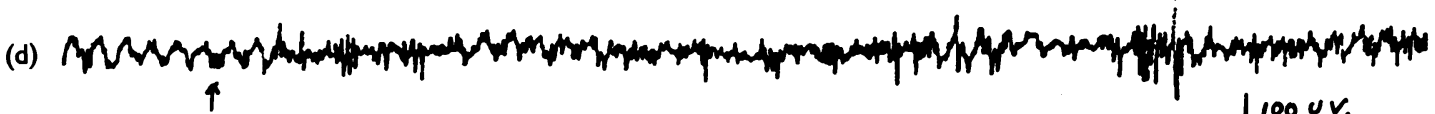

I SEC.

Fig. 4.-E.M.G. showing responses to neutral and stimulating words.

(a) Neutral word. Note slight depression of alpha activity; (b) " hospital "; (c) " blood" ; (d) " operation". In (d), muscle activity persisted for 15 seconds following the stimulus word. Stimuli marked by arrows.

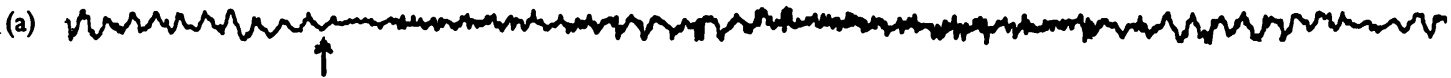

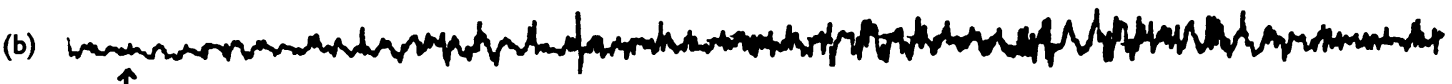
$\uparrow$

(c)

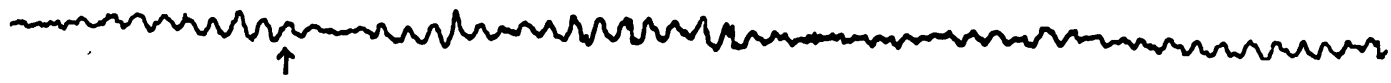

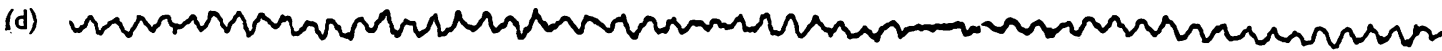
$\uparrow$

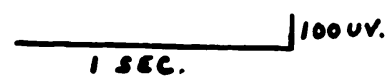

Fig. 5.-E.M.G. from Case J. O'B.

Stimulus words (a)"skin"-slight reaction; (b) "rash"-marked reaction; (c "love"-no reaction; (d) " passion"-no reaction.

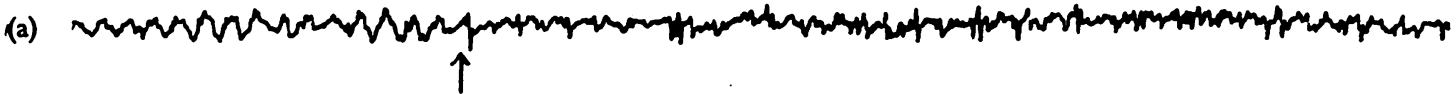

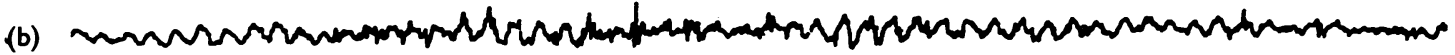
$\uparrow$

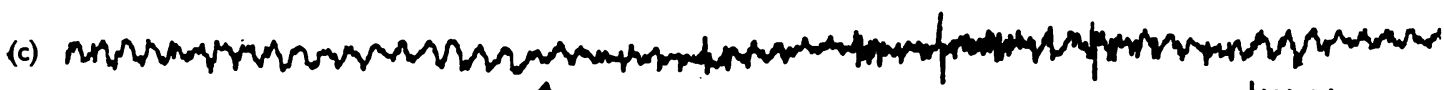
$\uparrow$ 100 uv.

FIG. 6.-E.M.G. from Case M.W. Reactions to stimulus words (a) "dance-hall" ; (b) " husband" ; (c) " fight". 
(a)

(

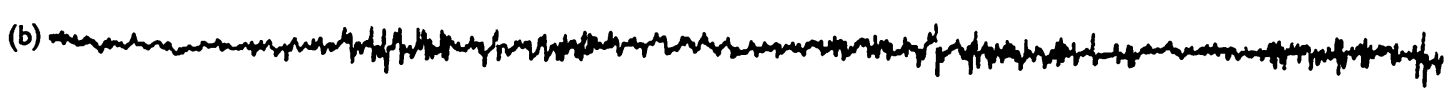

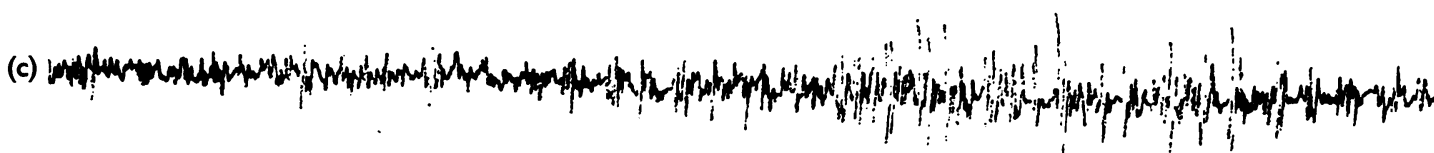

(d)

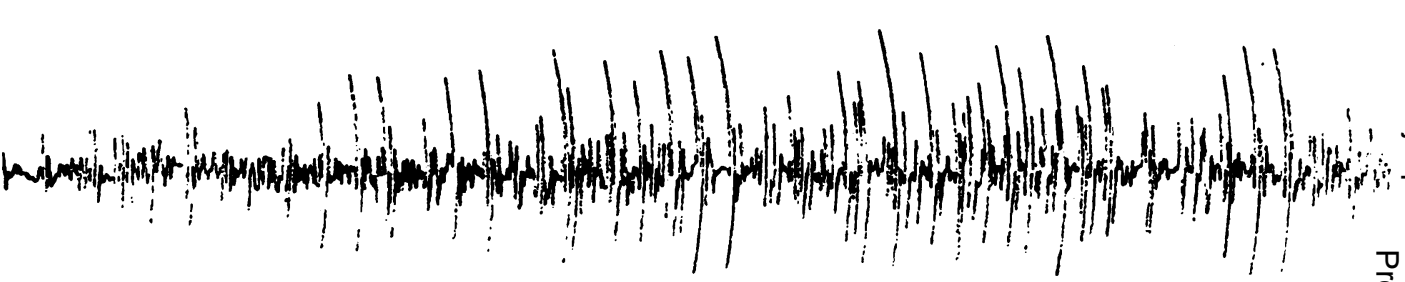

(e)

The

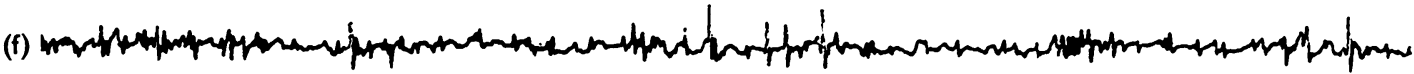

(g)

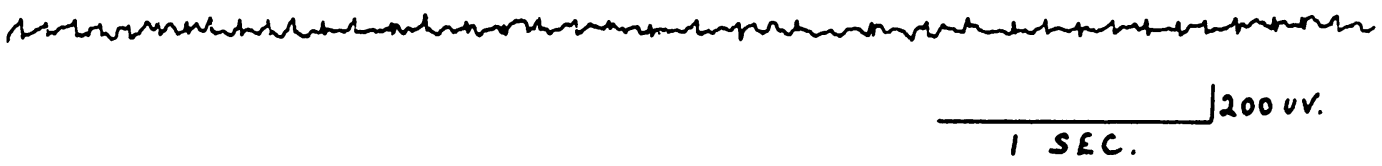

Fig. 7.-E.M.G. from spider reaction test (Case W.H.). Continuous record ; read from left to right.

(a) At the first arrow subject " sees" the spider, (b) spider " jumps" onto her leg, (c) "crawls" onto her arm and neck, (d) hairy spider, unable to brush it off, (e) spider is dead-second arrow, (f) out of sight, (g) subject relaxed. 


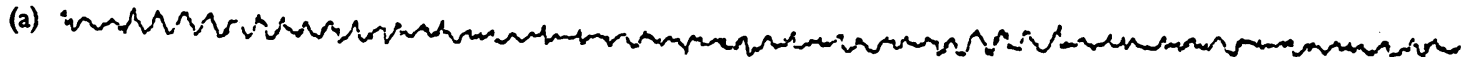

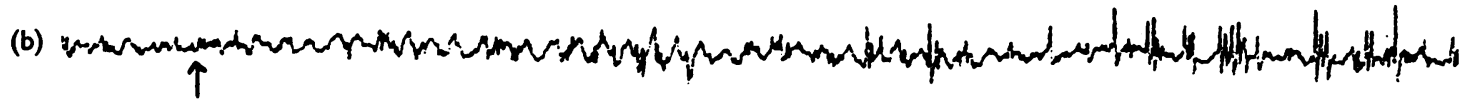

(c)

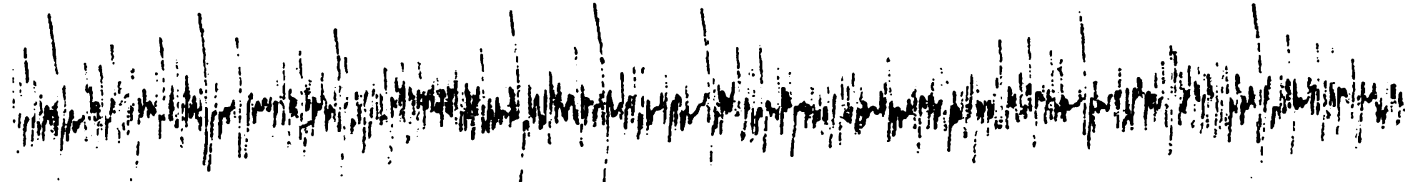

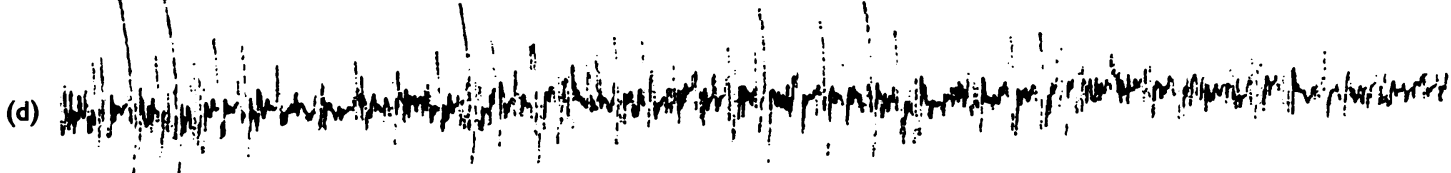

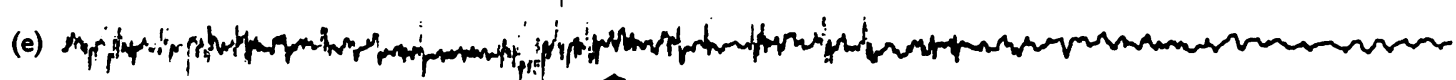
$\uparrow$

(f)

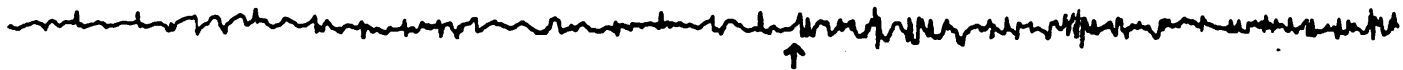

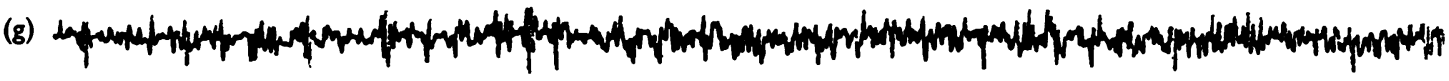

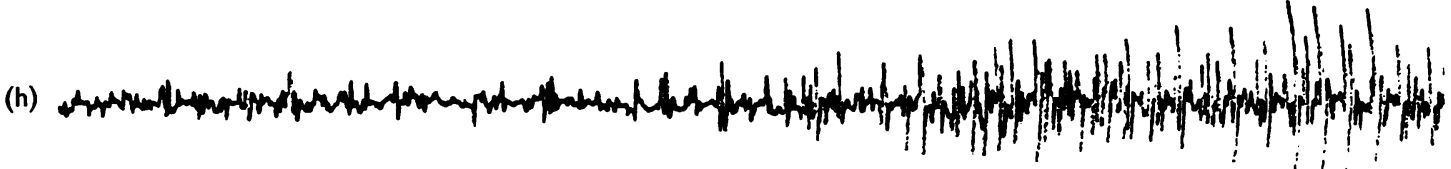

(i)

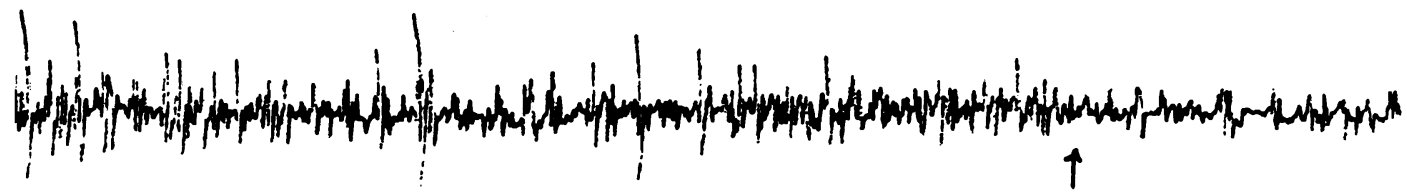

(j)

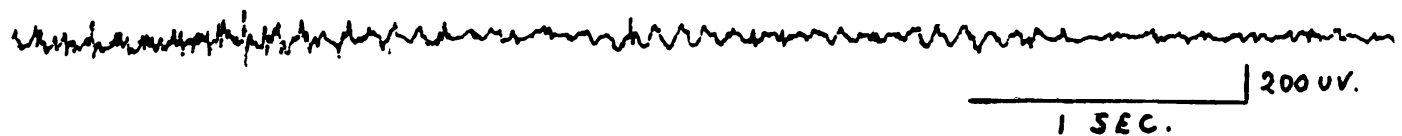

FIG. 8.-E.M.G. from excitement test (Case G.S.)

(a) Normal E.E.G.; excitement suggested at arrow in line b ; (c) very excited. Calm suggested at arrow in line e. Excitement repeated at arrow, line f. More excited, line g.; (h) very excited. Calm suggested at arrow in line i. Subject relaxed.

Continuous record, reading from left to right. 
(a) (n) $\uparrow$

(b)

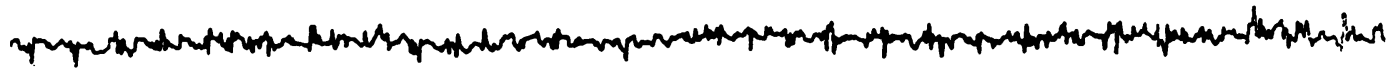

(c)

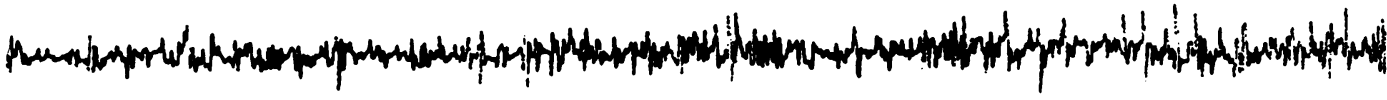

(d)

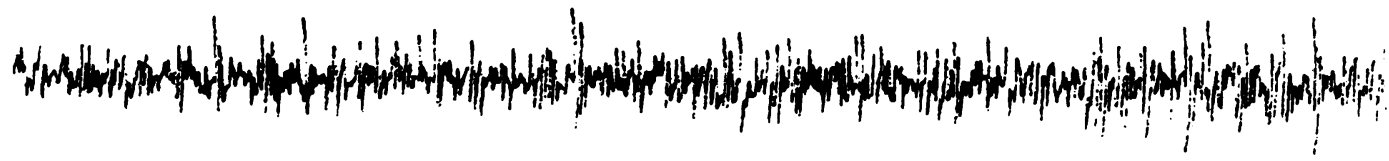

(e)

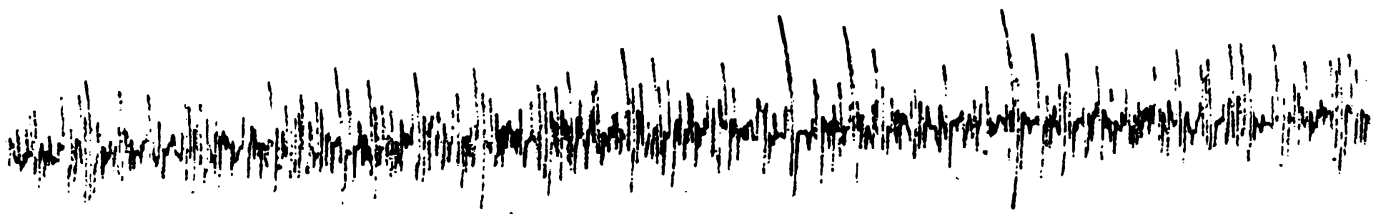

(f)

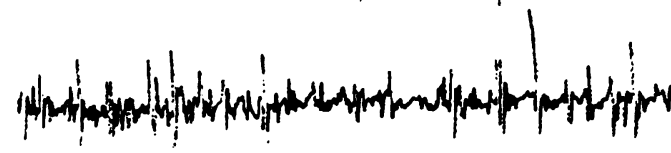

$200 \cup v$

$1 S E C$

Fig. 9.-E.M.G. from skin reaction test (Case L.H.). Continuous record read from left to right.

At the arrow in line a the appearance of a rash was suggested to the subject. Muscle action potentials appeared in the record following the stimulus word "rash", and the spikes increased in number, frequency, and amplitude with further suggestion. The rash was described in detail (line b), covering the subject's face (c), causing great swelling (d), and disfigurement (e), and finally disappearing completely (f). The emotional state induced in this experiment was measured by changes in pulse and respiratory rates, and in $\mathrm{CO}_{2}$ alveolar tension, although the subject claimed she had been unaware of any emotional disturbance.

record. Fig. 9 shows the E.M.G. response; $\mathrm{CO}_{2}$ analysis figures are given in Table $I$.

\section{TABLE I}

PHYSIOLOGICAL CHANGES ASSOCIATED WITH EMOTION*

\begin{tabular}{c|c|c|c|c}
\hline $\begin{array}{c}\text { Subject } \\
\text { L.H. }\end{array}$ & $\begin{array}{c}\text { E.M.G. } \\
\text { (Fig. 9) }\end{array}$ & $\begin{array}{c}\text { Tension } \\
\left(\mathrm{CO}_{2} \%\right)\end{array}$ & $\begin{array}{c}\text { Pulse } \\
\text { (per minute) }\end{array}$ & $\begin{array}{c}\text { Respiration } \\
\text { (per minute) }\end{array}$ \\
\hline Control & a & 5.49 & 78 & 14 \\
\hline Suggestion on & b, c, d, e & 2.95 & 90 & 21 \\
\hline Suggestion off & f & 4.9 & 72 & 14 \\
\hline
\end{tabular}

\section{Discussion}

In muscular activity, shortening or tension development may produce electrical changes, which can be recorded as muscle action potentials. These are diphasic or polyphasic responses, varying in frequency and amplitude according to the physiological state of the active muscle. Although skeletal muscle is normally under a slight mechanical tension even when at rest, no action potentials can be recorded from it in the relaxed state (Hoefer, 1941). The electroencephalogram is thus usually $\frac{O}{D}$ free from muscle artifacts while the subject is relaxed, $\stackrel{\varrho}{\rightarrow}$ and scalp electrodes are used in common practice. A $\overline{0}$ rise in tension of the scalp muscles, without any obvious movement, would not be noticeable to an observer and the subject is usually unaware of it. Tension changes, however small, can usually be detected by means of the electromyogram, and muscle spikes stand out quite clearly from the lower voltage rhythm of the cerebral cortex. The changes recorded in the active muscle fibres are limited to the $ᄋ$ vicinity of the electrodes. A slight increase in tension may produce a few action potentials, low in voltage, 음 indicating that only a few muscle units are active. $>$ This is shown in Fig. 2, where random spikes appear after the stimulus word "speech" and have an N amplitude of about $100 \mathrm{uV}$. With greater tension there is an increase in frequency and amplitude of 0 
the spikes (Fig. 4) and a strong stimulus is usually followed by a burst of action potentials of very high amplitude (up to $1.5 \mathrm{mv}$.) and frequencies up to 60 per second (Fig. 7).

The depression of alpha rhythm by certain stimulus words (Fig. 1) was first analysed by Adrian and Matthews (1934) and occurs for most attention stimuli involving intellectual activity; it may be correlated with the alpha block that occurs on opening the eyes. The only applicable significance concerns the duration of the block. The alpha waves were thought to be controlled by a subcortical pace-maker (Adrian and Matthews, 1934) and thus possibly related to subcortical nuclei involved in emotional responses. To test this relationship, Forbes and Andrews (1937) studied electroencephalograms with simultaneous observations on skin resistance but found no significant relationship between the depression of alpha rhythm and the psycho-galvanic response of the skin.

In contrast, the appearance of muscle action potentials is unmistakable evidence of increased activity in the muscle units underlying the electrodes. It remains to measure the degree of response, and to correlate these measurements with the emotional value of the stimulus words. In Series A normal electroencephalograms were obtained from all the subjects, and the records were relatively free from artifacts. Muscle potentials due to gross movements, e.g. coughing, yawning, are easily recognized. When the subject reacts to a stimulus word a weak reaction may give a few spikes only, but a strong reaction results in a persistence of the spike potentials for as long as the subject is able to concentrate or until another word is given. The potentials disappear when a neutral word is given but reappear when the stimulus word is repeated. It is suggested that the emotional value of a word is proportional to the persistence of the spikes. In Fig. 5 the response to the word "skin" is seen to last three seconds and to the word "rash" eight seconds. On the other hand the stimulus words "love" and "passion" evoke no response at all.

In Series B the records illustrate a method for measuring the degree of response to emotional situations.

Frequency.-The total number of muscle action potentials can be easily counted on the tracing which has a paper speed of $3 \mathrm{~cm}$. per second. The frequency may vary throughout the tracing, being generally low at first and subsequently increasing to a high rate according to the intensity of the stimulus. The discharge rate of each muscle unit increases as the tension increases. This is shown in Fig. 7. The spikes first appear with a frequency of 10 per second and soon reach a level of about 20 per second, which is then maintained.

Number of Spikes.-With increasing muscular activity the number of action potentials increases and becomes visible on the electromyogram. The ink-recorder is not faithful for high frequency discharges so that many action potentials are probably integrated and the number consequently reduced. The frequency response of the new muscle groups runs parallel with the initial motor neuron discharge, so that increased frequency becomes evident in all the active muscle units with increasing stimulation. These two factors, increased frequency of discharge and the recruitment of more muscle units, are the physiological response to a rise in stimulus intensity and this may be considered a true reflection of the emotional response of the subject.

Amplitude.-The size of the action potentials can be measured by reference to a calibrated input and it is seen that their voltage is much greater than that of the spontaneous cortical rhythm. Although the amplitude of a single motor unit does not vary with the intensity of the stimulus (Adrian and Bronk, 1929), when a record is taken from a large number of muscle units, using surface electrodes, the size of the action potentials apparently increases as many motor units will discharge in phase. This is demonstrated in Fig. 7. After the stimulus word "spider" the amplitude of the initial spikes is about 150 microvolts. As the emotional events are described and more muscle units become active, the amplitude reaches 1.5 millivolts. These larger spikes are the first to disappear as the stimulus is withdrawn and the tension relaxes.

Duration.-When a muscle is stimulated the appearance of action potentials, after a brief latency, indicates activity in one or more muscle fibres. With continued stimulation an increasing number of motor neurons becomes active until a stimulation plateau is reached and recruitment is maximal (Fig. 9e). When the stimulus is withdrawn the electromyogram may remain unaltered for a few seconds, and then follows a gradual falling away of activity until relaxation is complete. The duration of the response is a sign of continued muscular activity and is proportional to the intensity of the stimulus. In this way the emotional value of the stimulus can be readily assessed.

One of the most striking observations in all these experiments is the absence of other physical signs, which can be used with reliability. The subject is 
usually unaware of any emotional disturbance. There are no obvious respiratory, vascular, or cutaneous responses which can be used as an index of response. In rare cases, where the emotion is deep or excites violent reaction, there may be increased depth of breathing and increased pulse and respiratory rates. This is demonstrated in Table $\mathrm{I}$. During the height of the reaction the alveolar $\mathrm{CO}_{2}$ concentration was lowered from $5.49 \%$ to $2.95 \%$; the pulse rate increased from 78 per minute to 90 per minute; the respiratory rate also increased. Changes such as these are not easily induced in normal subjects ; they do not compare in simplicity, reliability, or effective standardization with electromyographic recordings.

The value of the method in clinical diagnosis must depend upon the development of a systematic technique and this paper does not attempt to assess its status in relation to other psycho-diagnostic techniques. It is not a measurement of personality though it may help to determine certain hidden aspects of the personality. In Fig. 6 reactions are shown to random-spaced stimulus words which were clearly associated without any concious control by the subject. The method has been limited to emotional states in normal subjects, and further experiments applied to abnormal populations may reveal useful information. Interpretation of the tracings requires no particular skill and is devoid of complexities of data, mathematical calculations, or conflicts arising from the personality of the examiner. The validity of electromyographic responses need not be questioned as they are based on recognized physiological principles concerned with the functional activity of skeletal muscle. The results of the present experiments indicate, therefore, that physio- $\bar{Z}$ logical tension in muscle is increased in emotional states and this tension can be recorded by electrical means. It remains for further experiment to determine the relation between the central mechanisms involved in mental activity and the peripheral of muscular response. Such experiments should help to elucidate the neurophysiological basis of many concepts of function associated with emotion.

\section{Summary}

A method is described for recording emotional responses in normal individuals. Leads are taken from the temporal muscles. In relaxed subjects an electroencephalogram is recorded, but with appropriate stimuli ; an electromyogram is superimposed on the tracing.

The degree of response is related to the frequency, number, amplitude, and duration of muscle action potentials.

Conscious control by the subject is minimal and insight may be gained into hidden aspects of personality.

The reliability and validity of the method are $\dot{\omega}$ indicated and its value in diagnosis and resear discussed.

\section{REFERENCES}

Adrian, E. D., and Bronk, D. W. (1929). J. Physiol., 67, 119.

- and Matthews, B. H. C. (1934). Brain, 57, 355.

Davis, F. H., and Malmo, R. B. (1951). Amer. J. Psychint., 107,

Forbes, T. W., and Andrews, H. L. (1937). Science. 86, 474.

Hoefer, P. F. A. (1941). Arch. Neurol. Psychiat. Chicago, 46, 947

Liberson, W. T. (1945). Dig. Neurol. Psychiat., 13, 594.

Lundervold A. (1952). J. nerv. ment. Dis., 115, 512.

Lume Nature of Human Conficts, or Emotif

Luria, A. R. (1932). The Nature of Human

Conflict and Will. Liveright, New York.
Peterson, F., and Jung, C. G. (1907). Brain, 30, 153.

Ruesch, J., and Finesinger, J. E. (1943). Arch. Neurol. Psychiat.,

4 Chicago, 50, 439.

Weddell, G., Feinstein, B., and Pattle, R. E. (1944). Brain, 67, 178.

\section{THE MAY (1953) ISSUE}

The May (1953) issue contains the following papers :-

The Prodromes to Cortical Localization. By Professor Sir Geoffrey Jefferson.

Studies in Traumatic Epilepsy. Part 2 : Focal Motor and Somatic Sensory Fits : A Study of 85 Cases. By W Ritchie Russell and C. W. M. Whitty.

Deposits of Fluorescent Acid-fast Products in the Nervous System and Skeletal Muscles of Adult Rats with Chronic Vitamin-E Deficiency. By Lárus Einarson.

An Extremely Rare Recessive Hereditary Syndrome Including Cerebellar Ataxis, Oligophrenia, Cataract, and Other Features. By Hugh Garland and Doreen Moorhouse.

The Radiological Appearances of Agenesis of the Corpus Callosum. By Philip Sheldon and Anthony Peyman.

A number of copies are still available and may be obtained from the Publishing Manager, British Medicaln Association, Tavistock Square, W.C.1, price 12s. $6 \mathrm{~d}$. 